\title{
Spectroscopic (analytical) approach to gunshot residue analysis for shooting distance estimation: a systematic review
}

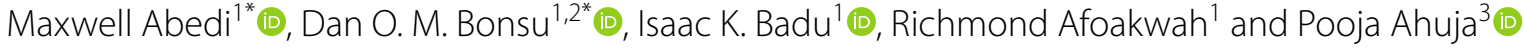

\begin{abstract}
Background: The determination of the shooting distance using gunshot residue (GSR) analysis is crucial in the investigation and reconstruction of firearm-related crimes. However, the conventional chemographic method for GSR analysis is destructive and has limited sensitivity and selectivity. While the spectroscopic method has potential in GSR analysis for crime investigation, there is a current lack of consistency in the spectroscopic results obtained for shooting distance estimation via GSR analysis. Addressing such limitations will enhance the forensic capabilities of law enforcement and provide an added advantage to crime laboratories during an investigation. It will also reinforce the use of such spectroscopic data in a criminal investigation.

Main text: We obtained all peer-reviewed articles relevant to shooting distance estimation from searching Scopus, Web of Science, PubMed, and Google Scholar databases. We specifically searched the databases using the keywords "shooting distance,"'range of fire," "gunshot residue," "firearm discharge residue," and "firearm-related crime" and obtained 3811 records. We further filtered these records using a combination of two basic keywords "gunshot residue" and "shooting distance estimations" yielding 108 papers. Following a careful evaluation of the titles, abstracts, and full texts, 40 original peer-reviewed articles on shooting distance estimation via GSR analysis were included in the study. The forgoing included additional sources $(n=5)$ we obtained from looking through the reference lists of the forensic articles we found.
\end{abstract}

Short conclusion: This paper discusses the current scope of research concerning the chemographic and spectroscopic analysis of GSR for shooting distance estimation. It also examines the challenges of these techniques and provides recommendations for future research.

Keywords: Forensic ballistics, Forensic science, Gunshot residue, Firearm discharge residue, Shooting distance estimation, Range of fire

\section{Background}

Firearm-related crimes (FRC) such as armed robbery, homicide, suicide, and mass shootings threaten global public security and safety (Hemenway and Miller 2000).

\footnotetext{
*Correspondence: maxwell.abedi@ucc.edu.gh; dbonsu@ucc.edu.gh ${ }^{1}$ Department of Forensic Sciences, University of Cape Coast, Cape Coast, Ghana

${ }^{2}$ School of Biological Sciences, The University of Adelaide, Adelaide,

South Australia, Australia

Full list of author information is available at the end of the article
}

An estimated 18,000 children and adolescents die yearly in the US via injuries resulting from accidental gun firing (Cunningham et al. 2018). The foregoing is a consequence of the ease of access due to lax regulations on firearm possession (Hemenway and Miller 2000) and the influx of improvised/makeshift, including 3D printed (Chase and Laporte 2018; Walther 2015) and illegal firearms. In Ghana, an estimated 1.1 million unregistered firearms are illegally in civilian possession and have been implicated in the recent surge in FRC (Bokpe 2016). 
Analysis of gunshot residues (GSR) from discharged firearms is vital in ballistic reconstruction in instances of FRC (Chang et al. 2013a, 2013b; Saverio Romolo and Margot 2001). Notably, the shooting distance, time since firearm discharge, ammunition type, trajectory or spatial position of the discharged firearm relative to its environment and target, injury pattern reconstruction, and linking an individual to gun use (Chang et al. 2013a, 2013b; Saverio Romolo and Margot 2001) can be estimated via GSR analysis. Gunshot residue mainly comprises burnt, unburnt, and partially burnt propellant charge, smoke, a cloud of vapor, and metal particles from the ammunition, and even the firearm (Dalby et al. 2010; López-lópez and García-ruiz 2014; Muller et al. 2007; Saverio Romolo and Margot 2001; Turillazzi et al. 2013). In addition, dispersion and deposition of GSR on the targets may be impacted by the environmental conditions and/or physical activities of the shooter (Zuzanna Brozek-Mucha 2011; Jalanti et al. 1999).

Consequently, shooting distance may be estimated by a visual comparison of casework GSR pattern with that generated from test-firing using the same firearm and ammunition involved in the crime (Capannesi et al. 1993; Dalby et al. 2010; López-lópez and García-ruiz 2014; Muller et al. 2007). Visualizing the GSR pattern on the victim of a crime is conventionally based on laborintensive and subjective chemographic techniques (presumptive color test) (López-lópez and García-ruiz 2014). Despite their continued use in casework (Martiny et al. 2008), such color tests are not only destructive but have limited sensitivity and selectivity. Furthermore, the lack of efficiency in pattern enhancement of GSR from leadfree ammunition or nontoxic ammunition (Berendes et al. 2006) precludes recognition of chemographic tests as robust.

Analytical techniques based on spectroscopy have found utility in GSR analysis with promising results (Barth et al. 2012; Zuzanna Brozek-Mucha 2014; Cecchetto et al. 2011; Leiva et al. 2019; Santos et al. 2007; Zeichner 2003; Zeichner and Glattstein 2002). Particularly, the coupling of scanning electron microscope with energy-dispersive X-ray spectroscopy (SEM-EDS) has emerged as the technique of choice (Zuzanna BrozekMucha 2014; French and Morgan 2015). The SEM-EDS allows for both elemental composition and morphological examination of the characteristic primer GSR, typically lead $(\mathrm{Pb})$, barium $(\mathrm{Ba})$, and antimony $(\mathrm{Sb})$. Additionally, the technique is also spatially discriminating, non-destructive, and requires no sample preparation $(\mathrm{Z}$. Brozek-Mucha 2000; Zuzanna Brozek-Mucha 2009, 2014; Dalby et al. 2010; Saverio Romolo and Margot 2001).

The merits, notwithstanding, spectroscopic analysis of GSR for shooting distance estimation (SDE) remain inconsistent. For example, while Gagliano-candela, Colucci, and Napoli claimed that atomic absorption spectroscopy (AAS) could estimate shooting distances up to $100 \mathrm{~cm}$ from the target, Gradaščević et al. showed that AAS was only effective up to $10 \mathrm{~cm}$. This review discusses the conventional and modern techniques of GSR analysis for SDE; it also identifies challenges and gap in existing methods and provide a perspective on future direction.

\section{Main text}

\section{Literature collection}

All peer-reviewed articles relevant to SDE were obtained from searching Scopus, Web of Science, PubMed, and Google Scholar databases. We specifically searched the databases using the keywords "shooting distance," "range of fire," "gunshot residue," "firearm discharge residue," and "firearm-related crime" and obtained 3811 records (Scopus, $n=10$; Web of Science, $n=33$; PubMed, $n=28$; Google scholar, $n=3740$ ). We further filtered these records using a combination of two basic keywords "gunshot residue" and "shooting distance estimation" yielding 108 papers. After screening the titles and abstracts, we only included full-text articles describing original research that focused on GSR analysis for SDE $(n=40)$ in this study. The foregoing included additional sources obtained from the reference list of one original article $(n=5)$. We excluded supplementary published works, reviews, conference abstracts, discussion papers, editorials, errata, short communications, correspondence, and news. The search strategy is shown in Fig. 1.

\section{Results}

\section{GSR analysis for SDE}

The distance between the gun's muzzle end and the target is termed shooting distance or range of fire or muzzle-totarget distance. In the investigation and reconstruction of the FRC, determining the shooting distance is critical. The GSR exits the firearm through the muzzle end (and other openings in the firearm), travels a little distance before settling on the victim, and surfaces close to the firing site (Gallidabino et al. 2016). As a result, the relevance of the distance traveled by these residues cannot be ignored, given its critical significance in the investigation and reconstruction of shooting incidents. The methods used for GSR analysis for SDE can be categorized as chemographic or spectroscopic.

\section{Chemographic analysis of GSR for SDE}

The chemographic methods (Table 1) for GSR analysis relies on a color formation following a chemical reaction between a specific reagent and the metal elements in the GSR sample (Ananth et al. 2014; Chang et al. 2013a, 2013b; Niewoehner 2015; Saverio Romolo and Margot 


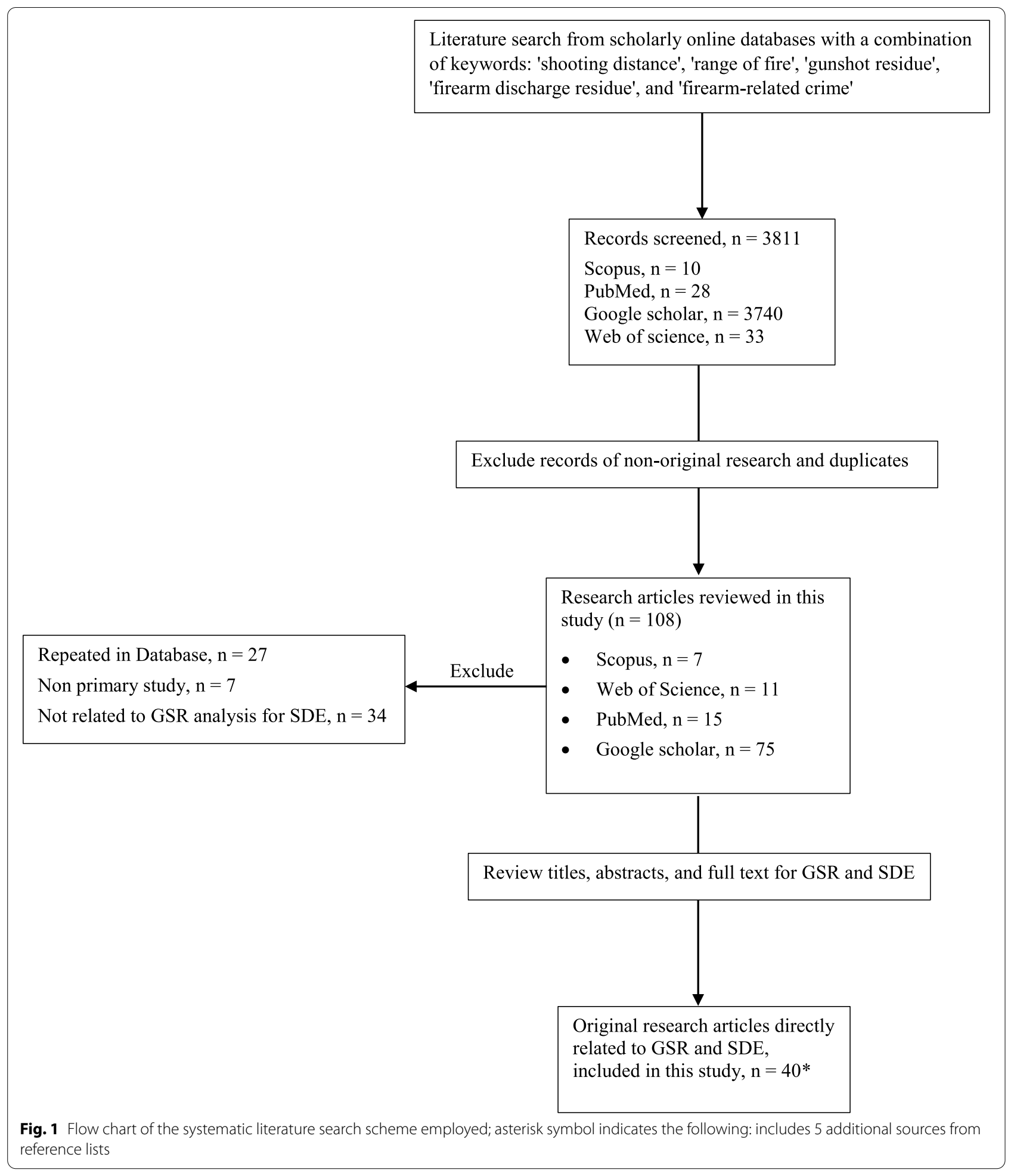

2001; Schwoeble and Exline 2000; Tugcu et al. 2006; Zeichner and Glattstein 2006; Niewoehner 2015; Dalby et al. 2010). Thus, the technique is suitable for detecting both inorganic (metallic) and organic elements in GSR particles.

Although the chemographic method is still used in casework for presumptive identification of a sample as 
Table 1 Chemographic method for GSR analysis

\begin{tabular}{|c|c|c|c|c|}
\hline Reference & Test type & Compound detected & Reagent used & Description/color reaction \\
\hline $\begin{array}{l}\text { Ananth, Kalthom, and Me } \\
\text { (Ananth et al. 2014) }\end{array}$ & Dermal nitrate/paraffin test & Nitrate & $\begin{array}{l}\text { Diphenylamine dissolved in } \\
\text { strong sulfuric acid }\end{array}$ & $\begin{array}{l}\text { Picked up GSR on paraffin wax } \\
+ \text { reagent gives a blue color } \\
\text { spot indicating the presence } \\
\text { of nitrates }\end{array}$ \\
\hline $\begin{array}{l}\text { Chang, Jayaprakash, and } \\
\text { Yew (Chang et al. 2013a, b) }\end{array}$ & Spot test & Lead $(\mathrm{Pb})$ & Sodium rhodizonate & $\begin{array}{l}\text { GSR sample + reagent gives a } \\
\text { pink coloration indicating the } \\
\text { presence of lead. }\end{array}$ \\
\hline $\begin{array}{l}\text { Saverio Romolo and Margot } \\
(2001)\end{array}$ & $\begin{array}{l}\text { Walker test/Marshal and } \\
\text { Tewari test }\end{array}$ & Nitrite & $\begin{array}{l}\text { 2-Naphthylamine sulfanilic } \\
\text { acid and citric acid }\end{array}$ & $\begin{array}{l}\text { GSR sample + reagent gives } \\
\text { a pink coloration for the pres- } \\
\text { ence of nitrite }\end{array}$ \\
\hline Ananth et al. (2014) & Modified Griess test & Nitrite & Griess reagent $^{a}$ & $\begin{array}{l}\text { GSR sample + reagent gives } \\
\text { a rose color for the presence } \\
\text { of nitrite }\end{array}$ \\
\hline Dalby et al. (2010) & Harrison and Gilroy's test & $\begin{array}{l}\text { Lead }(\mathrm{Pb}) \text {, barium }(\mathrm{Ba}) \text {, } \\
\text { and antimony }(\mathrm{Sb})\end{array}$ & $\begin{array}{l}\text { - Triphenyl methylarsonium } \\
\text { iodide alcoholic solution } \\
\text { - Sodium rhodizonate } \\
\text { - Dilute hydrochloric acid }\end{array}$ & $\begin{array}{l}\text { GSR sample + triphenyl } \\
\text { methylarsonium iodide alco- } \\
\text { holic solution gives orange } \\
\text { ring color for the presence } \\
\text { of Sb. Two drops of sodium } \\
\text { rhodizonate are added to the } \\
\text { center of the orange ring, } \\
\text { color changes to red for Pb or } \\
\text { Ba or both. A drop of dilute } \\
\text { hydrochloric acid is added to } \\
\text { the red spot, color changes to } \\
\text { blue for Pb. No color change is } \\
\text { indicative of Ba }\end{array}$ \\
\hline Ananth et al. (2014) & Lunge test ${ }^{\mathrm{b}}$ & Nitrocellulose (NC) & Lunge reagent & $\begin{array}{l}\text { GSR sample + reagent gives a } \\
\text { red azo color for NC }\end{array}$ \\
\hline Niewoehner (2015) & Zincon reagent test ${ }^{c}$ & Zinc (Zn) and titanium (Ti) & Zincon reagent & $\begin{array}{l}\text { GSR sample + reagent gives a } \\
\text { blue-colored complex for } \mathrm{Zn} \\
\text { and } \mathrm{Ti}\end{array}$ \\
\hline
\end{tabular}

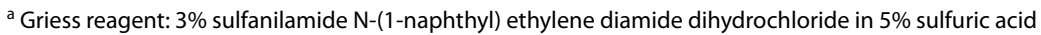

${ }^{\mathrm{b}}$ Detect organic compounds (NC) in GSR

${ }^{c}$ Applied to $\mathrm{Pb}$-free ammunition, e.g., Sintox ammunition

GSR, its application in SDE has been limited and problematic. For instance, Marty, Sigrist, and Wyler determined the shooting distance (differentiated between close range and far range shot) using the rhodizonate staining technique on skin samples. The use of skin samples in this scenario increases the likelihood of generating a false positive result since the sodium rhodizonate reagents also produce positive results with keratinous structures of hair follicles (Andreola et al. 2011). The above technique was improved further via a heated press for the transference of GSR particles on clothing items for SDE (Geusens et al. 2019). Furthermore, Vinokurov, Zelkowicz, Udi, and Zeichner proposed a technique based on the influence of contamination of a victim's clothing by GSR for a range of fire estimation using the modified Griess test (MGT) method. The detection of nitrite using the MGT method follows the reaction of the GSR sample with potassium hydroxide solution plus the MGT reagent (Atwater et al. 2006). While the MGT is effective, a method that reveals the GSR pattern on an item without chemicals or reagents would be preferable. Not only would this save time on reagent preparation, but it will also alleviate contrast problems when the GSR is present on a multi-colored fabric or target (Bailey et al. 2004).

\section{Spectroscopic analysis of GSR for SDE}

The spectroscopic technique deals with the interaction between specific electromagnetic radiation and the GSR sample. This technique estimates the concentration and yields information about the elemental composition (for example, $\mathrm{Pb}, \mathrm{Ba}$, and $\mathrm{Sb}$ ) of the GSR sample. Spectroscopic techniques employed for GSR analysis to estimate the shooting distance are presented in Table 2.

One of the earliest studies on SDE evaluated the concentration and pattern of $\mathrm{Sb}$ deposited around a bullet entrance hole using neutron activation analysis (NAA) at a firing distance of $16.5 \mathrm{~cm}$ and $26.7 \mathrm{~cm}$ for a first and second shot, respectively (Capannesi et al. 1993). Neutron activation analysis (NAA) is an isotope-based technique that works by bombarding stable atomic nuclei 


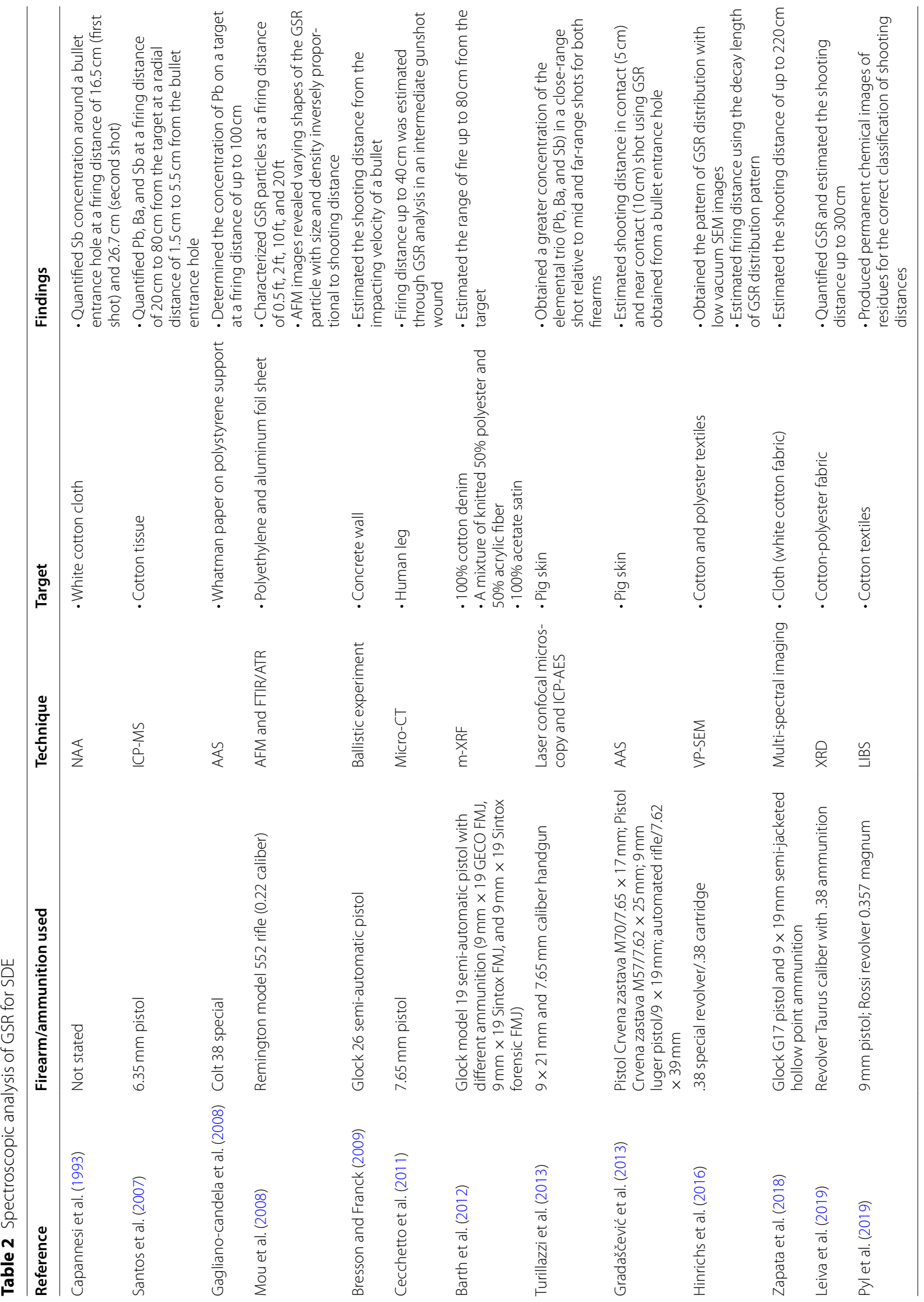


with neutrons (from a nuclear reactor) and measuring the energy and half-life of the emitted radiation (radioactive gamma rays) following the decay process (Greenberg et al. 2011). During GSR analysis, the technique exclusively measures the presence of radioactive $\mathrm{Sb}$ $\left(\mathrm{Sb}_{121} \rightarrow \mathrm{Sb}_{122}\right)$ and $\mathrm{Ba}\left(\mathrm{Ba}_{132} \rightarrow \mathrm{Ba}_{133}\right)$. It is particularly sensitive and capable of analyzing difficult to dissolve elements (such as inorganic GSR) without sample pretreatment. However, apart from the relatively slow sample throughput, the method does not apply to the analysis of $\mathrm{Pb}$ and requires a powerful neutron source like a nuclear reactor. These limitations notwithstanding, NAA has been used in GSR analysis for forensic investigations (Chohra et al. 2015). The inductively coupled plasmamass spectroscopy (ICP-MS) platform allows the examiner to obtain a very low detection limit due to its high sensitivity and facilitates rapid multi-elemental analysis, giving both qualitative and quantitative outputs (Biegstraaten and Horváth 2007). Excepting the high cost and the occurrence of spectral and non-spectral interferences during sample analysis, ICP-MS has proven invaluable for GSR analysis. Santos et al. used ICP-MS to profile the simultaneous presence of GSR elemental trio $(\mathrm{Pb}, \mathrm{Ba}$, and $\mathrm{Sb}$ ) at a firing distance of not more than $80 \mathrm{~cm}$ away from the target. This finding supports the work of Barth et al. whose study estimated the shooting distance from GSR using milli-X-ray fluorescence ( $m$-XRF). Unlike the ICP-MS, $\mathrm{m}$-XRF is non-destructive, does not consume samples under examination, and efficiently detects and visualizes particles from $\mathrm{Pb}$-free or nontoxic ammunition (example, sintox ammunition). Leiva et al. also estimated the shooting distance (between 5 and $300 \mathrm{~cm}$ ) using $\mathrm{x}$-ray diffraction (XRD) analysis.

Turillazzi et al. employed confocal laser microscopy and inductively coupled plasma with atomic emission spectroscopy (ICP-AES) to estimate the shooting distance and reported obtaining a greater concentration of $\mathrm{Pb}, \mathrm{Ba}$, and $\mathrm{Sb}$ in a close-range shot relative to mid and far range shot. The elemental trio $(\mathrm{Pb}, \mathrm{Ba}$, and $\mathrm{Sb})$ establishes the identity of a sample as GSR. Further, a combination of micro-computed tomography (microCT) and image analysis software was used to quantify GSR present in a mid-range gunshot wound for SDE ( $\leq$ $40 \mathrm{~cm}$ ) (Cecchetto et al. 2011). Although little data was presented on the elemental trio $(\mathrm{Pb}, \mathrm{Ba}$, and $\mathrm{Sb})$ unique to primer GSR, the authors used human skin samples, representing an ideal simulation of real-life crime scene scenarios. Whereas the micro-CT technique is nondestructive (Cnudde et al. 2008), it has an increased likelihood of providing false-positive results (Cecchetto et al. 2011). Additionally, a multi-spectral imaging technique was effectively used for estimating the shooting distance (from 10 to $220 \mathrm{~cm}$ ) following GSR analysis (Zapata et al.
2018). This technique has the added advantage of automatically examining GSR patterns through quantitative approaches.

Atomic absorption spectroscopy (AAS) works by measuring the amount of electromagnetic radiation (ultraviolet-visible radiation) absorbed by free atoms in a gaseous state (Yeung et al. 2017). A study by Gagliano-candela, Colucci, and Napoli concerning SDE extrapolated the firing distance (up to $100 \mathrm{~cm}$ ) by analyzing the concentration of only $\mathrm{Pb}$ on a target using AAS. This result is consistent with the work of Gradaščević et al. (2013). Mou, Lakadwar, and Rabalais employed atomic force microscopy (AFM) and Fourier transform infrared attenuated total reflectance (FTIR/ATR) for SDE. Although the firing distance was estimated at $0.5 \mathrm{ft}(15.24 \mathrm{~cm}), 2 \mathrm{ft}$ $(60.96 \mathrm{~cm}), 10 \mathrm{ft}(304.8 \mathrm{~cm})$, and $20 \mathrm{ft}(609.6 \mathrm{~cm})$ away from the target, the authors argued that characterization of the specific element in the GSR sample was not successful with FTIR/ATR. The FTIR/ATR technique is very sensitive, considering its ability to quantify GSR particles at a range up to $20 \mathrm{ft}(609.6 \mathrm{~cm})$ from the target. The FTIR/ATR can also produce a profile unique to the ammunition type, making it a valuable tool for differentiating ammunitions based on the GSR particles (Mou et al. 2008).

The impact velocity of a full metal jacketed (FMJ) $9 \mathrm{~mm}$ Parabellum bullet was determined through a series of shooting experiments by comparing a questioned bullet to a set of test-fired bullets striking a wall (Bresson and Franck 2009). The firing distance was subsequently estimated from the impact velocity after evaluating the bullet's behavior (Bresson and Franck 2009). A variable pressure scanning electron microscope (VP-SEM) with characteristic high-resolution imaging and depth of field was introduced by Hinrichs et al. for SDE. This was achieved by establishing an exponential decay of the GSR distribution pattern on a target as a function of the radial distance of the particles from the bullet entry hole (Hinrichs et al. 2016). Pyl et al. showed that laser-induced breakdown spectroscopy (LIBS) is suitable for SDE. The LIBS performs better than the conventional chemographic technique in sensitivity, selectivity, reproducibility, accuracy, and multi-elemental detection capabilities (Pyl et al. 2019).

\section{Limitations and future directions}

Current research on GSR analysis for SDE has focused on collecting samples after test shots/firing in a controlled, indoor firing range. Whereas the findings from such studies are useful as proof of concept, it lacks practical applications in forensic casework scenarios where shootings may occur in an outdoor space exposed to natural environmental conditions. Therefore, extensive research 
is needed to study and understand the influence of environmental factors such as wind, temperature, rain, and humidity on the persistence and collection of GSR from a target. Further, the firearms and ammunition, range of fire, and spectroscopic technique employed varied from one study to another. Although such an approach is laudable, it has limited reproducibility for SDE. Hence, ensuring consistency and reliability in the spectroscopic results acquired for SDE will reinforce the use of such spectroscopic data in a criminal investigation. Also, extensive research and collaboration among practitioners are required to address the current lack of consensus on validated protocols, quality standards, and guidelines for interpreting spectroscopic results following GSR analysis for SDE.

\section{Conclusions}

The determination of shooting distance is a critical problem in firearm-related incidents where GSR is the only available evidence of probative value. Establishing the muzzle-to-victim distance through GSR analysis may contribute to linking a suspect to a shooting scene. However, the application of spectroscopy for SDE via GSR analysis in casework is limited due to the inconsistency in methods and lack of standardization and guidelines for interpreting results. In this paper, we have discussed the current scope of research concerning the chemographic and spectroscopic analysis of GSR for SDE, highlighted some limitations, and suggested further research directions to address them. Addressing such limitations will enhance the forensic capabilities of law enforcement and provide an added advantage to crime laboratories during an investigation.

\begin{abstract}
Abbreviations
FRC: Firearm-related crime; GSR: Gunshot residue; SDE: Shooting distance estimation; AAS: Atomic absorption spectroscopy; SEM-EDS: Scanning electron microscope with energy-dispersive X-ray spectroscopy; ICP-MS: Inductively coupled plasma with mass spectroscopy; ICP-AES: Inductively coupled plasma with atomic emission spectroscopy; NAA: Neutron activation analysis; m-XRF: Milli X-ray fluorescence; XRD: X-ray diffraction; AFM: Atomic force microscopy; FTIR/ATR: Fourier transform infrared attenuated total reflectance; FMJ: Full metal jacketed; VP-SEM: Variable pressure scanning electron microscope; LIBS: Laser-induced breakdown spectroscopy; MGT: Modified Griess test; NC: Nitrocellulose; Pb: Lead; Ba: Barium; Sb: Antimony; Zn: Zinc; Ti: Titanium.
\end{abstract}

\section{Acknowledgements}

Not applicable

\section{Authors' contributions}

$M A$ and $\mathrm{DOMB}$ contributed to the conception of the article, research for the article, drafting of manuscript, review, and editing of the manuscript; IKB, RA, and PA contributed to the drafting of paper, review, and editing of the paper. All authors read and approved the final manuscript.

Funding

Not applicable
Availability of data and materials

Not applicable

\section{Declarations}

Ethics approval and consent to participate

Not applicable

\section{Consent for publication \\ Not applicable}

\section{Competing interests}

No potential conflict of interest was reported by the authors.

\section{Author details}

${ }^{1}$ Department of Forensic Sciences, University of Cape Coast, Cape Coast, Ghana. ${ }^{2}$ School of Biological Sciences, The University of Adelaide, Adelaide, South Australia, Australia. ${ }^{3}$ School of Forensic Sciences, National Forensic Sciences University, Gandhinagar, India.

Received: 23 August 2021 Accepted: 1 November 2021

Published online: 16 November 2021

\section{References}

Ananth V, Kalthom U, Me S (2014) Detection of organic gunshot residues for the estimation of firing distance

Andreola S, Gentile G, Battistini A, Cattaneo C, Zoja R (2011) Forensic applications of sodium rhodizonate and hydrochloric acid: a new histological technique for detection of gunshot residues. J Forensic Sci 56(3):771-774. https://doi.org/10.1111/j.1556-4029.2010.01689.x

Atwater CS, Durina ME, Durina JP, Blackledge RD (2006) Visualization of gunshot residue patterns on dark clothing. J Forensic Sci 51(5):1091-1095. https://doi.org/10.1111/j.1556-4029.2006.00226.x

Bailey JA, Casanova RS, Bufkin K (2004) A comparison between the modified griess test and use of sodium hypochlorite for enhancement of gun shot residue patterns on fabric 1. Am Acad Forensic Sci:38-40

Barth M, Niewo L, Latzel S, Neimke D (2012) Shooting distance determination by $\mathrm{m}-\mathrm{XRF}$ - examples on spectra interpretation and range estimation. Forensic Sci Int 223:273-278. https://doi.org/10.1016/j.forsc iint.2012.10.001

Berendes A, Neimke D, Schumacher R, Barth M (2006) A versatile technique for the investigation of gunshot residue patterns on fabrics and other surfaces: m-XRF. J Forensic Sci 51(5):1085-1090. https://doi.org/10. 1111/j.1556-4029.2006.00225.x

Biegstraaten J, Horváth R (2007) Chemometric classification of gunshot residues based on energy dispersive $X$-ray microanalysis and inductively coupled plasma analysis with mass-spectrometric detection. 62:1028-1036. https://doi.org/10.1016/j.sab.2007.04.005

Bokpe, S. J. (2016). 1,300 Guns burnt but 1.1 million firearms in wrong hands-Small Arms Commission. Retrieved from https://www.graphic. com.gh/news/general-news/1-\%0A300-guns-burnt-but-1-1-millionfirearms-in-wronghands-\%0Asmall-arms-commission.html Assessed May 31, 2021

Bresson F, Franck O (2009) Estimating the shooting distance of a 9-mm Parabellum bullet via ballistic experiment. Forensic Sci Int 192:18-21. https:// doi.org/10.1016/j.forsciint.2009.07.018

Brozek-Mucha Z (2000) SEM-EDX study of inorganic gunshot residues from Makarov 9 mm ammunition. Z Zagadnien Nauk Sadowych 41:62-86

Brozek-Mucha Z (2009) Distribution and properties of gunshot residue originating from a Luger $9 \mathrm{~mm}$ ammunition in the vicinity of the shooting gun. Forensic Sci Int 183(1-3):33-44. https://doi.org/10.1016/j.forsciint. 2008.10.010

Brozek-Mucha Z (2011) Chemical and morphological study of gunshot residue persisting on the shooter by means of scanning electron microscopy and energy dispersive X-ray spectrometry. Microscopy Microanalysis 17(6):972-982. https://doi.org/10.1017/S1431927611012141 
Brozek-Mucha Z (2014) On the prevalence of gunshot residue in selected populations - an empirical study performed with SEM-EDX analysis. Forensic Sci Int 237:46-52. https://doi.org/10.1016/j.forsciint.2014.01.020

Capannesi G, Ciavola C, Sedda AF (1993) Determination of firing distance and firing angle by neutron activation analysis in a case involving gunshot wounds. Forensic Sci Int 61(2-3):75-84. https://doi.org/10.1016/03790738(93)90216-W

Cecchetto G, Giraudo C, Amagliani A, Viel G, Fais P, Cavarzeran F et al (2011) Estimation of the firing distance through micro-CT analysis of gunshot wounds. Int J Legal Med 125(2):245-251. https://doi.org/10.1007/s00414-010-0533-6

Chang KH, Jayaprakash PT, Yew CH (2013a) Gunshot residue analysis and its evidential values: a review, p 0618. https://doi.org/10.1080/00450618.2012. 691546

Chang KH, Jayaprakash PT, Yew CH, Abdullah AFL (2013b) Gunshot residue analysis and its evidential values: a review. Austr J Forensic Sci 45(1):3-23. https:// doi.org/10.1080/00450618.2012.691546

Chase RJ, Laporte G (2018) The next generation of crime tools and challenges: 3D printing. NIJ J 279:49-57

Chohra M, Beladel B, Baba Ahmed L, Mouzai M, Akretche D, Zeghdaoui A et al (2015) Study of gunshot residue by NAA and ESEM/EDX using several kinds of weapon and ammunition. J Radiat Res Applied Sci 8(3):404-410. https:// doi.org/10.1016/j.jrras.2015.02.012

Cnudde V, Masschaele B, De Cock H, Olstad VL, J. P. (2008) Virtual histology by means of high-resolution X-ray CT. J Microsc 232(May):476-485

Cunningham RM, Walton MA, Carter PM (2018) The major causes of death in children and adolescents in the United States. N Engl J Med 379(25):2468-2475. https://doi.org/10.1056/nejmsr1804754

Dalby O, Butler D, Birkett JW (2010) Analysis of gunshot residue and associated materials - a review. J Forensic Sci 55(4):924-943. https://doi.org/10.1111/j. 1556-4029.2010.01370.x

French J, Morgan R (2015) An experimental investigation of the indirect transfer and deposition of gunshot residue: Further studies carried out with SEMEDX analysis. Forensic Sci Int 247:14-17. https://doi.org/10.1016/j.forsciint. 2014.10.023

Gagliano-candela R, Colucci AP, Napoli S (2008) Determination of firing distance . lead analysis on the target by atomic absorption spectroscopy (AAS). J Forensic Sci 53(2):321-324. https://doi.org/10.1111/j.1556-4029.2008. 00668.x

Gallidabino M, Romolo FS, Weyermann C (2016) Time since discharge of 9 mm cartridges by headspace analysis, part 2 : ageing study and estimation of the time since discharge using. Forensic Sci Int. https://doi.org/10.1016/j. forsciint.2016.12.027

Geusens N, Nys B, Sebastien C (2019) Implementation and optimization of the sodium-rhodizonate method for chemographic shooting distance estimation. J Forensic Sci 5:5-8. https://doi.org/10.1111/1556-4029.13984

Gradaščević A, Resić E, Sarajlić N, Franjić B, Salkić A, Džuzdanović-Pašalić A (2013) Is it possible to determine firearm calibre and shooting range from the examination of gunshot residue in close range gunshot wounds? An experimental study. J Health Sci 3(3):232-237. https://doi.org/10.17532/ jhsci.2013.113

Greenberg RR, Bode P, De Nadai Fernandes EA (2011) Neutron activation analysis: a primary method of measurement. Spectrochim Acta Part B Atomic Spectrosc 66(3-4):193-241. https://doi.org/10.1016/j.sab.2010.12.011

Hemenway D, Miller M (2000) Firearm availability and homicide rates across 26 high- income countries. J Trauma 49(2):985-988

Hinrichs R, Frank PO, Vasconcellos MAZ (2016) Short range shooting distance estimation using variable pressure SEM images of the surroundings of bullet holes in textiles. Forensic Science Int. https://doi.org/10.1016/j.forsciint.2016. 12.033

Jalanti T, Henchoz P, Gallusser A, Bonfanti MS (1999) First Meeting of the European Academy of Forensic Sciences, Lausanne, Switzerland, 1997: The persistence of gunshot residue on shooters' hands. Sci Justice J Forensic Sci Soc 39(1):48-52. https://doi.org/10.1016/s1355-0306(99)72014-9

Leiva K, Ortega-ojeda FE, García-ruíz C (2019) Chemometrics and Intelligent Laboratory Systems Shooting distance estimation based on gunshot residues analyzed by XRD and multivariate analysis. 193(August). https://doi. org/10.1016/j.chemolab.2019.103831
López-López M, Alvarez-Llamas C, Pisonero J, García-Ruiz C, Bordel N (2017) An exploratory study of the potential of LIBS for visualizing gunshot residue patterns. Forensic Sci Int 273:124-131. https://doi.org/10.1016/j.forsciint 2017.02.012

López-lópez M, García-ruiz C (2014) Recent non-chemical approaches to estimate the shooting distance. Forensic Sci Int. https://doi.org/10.1016/j.forsc iint.2014.03.023

Martiny A, Campos APC, Sader MS, Pinto MAL (2008) SEM/EDS analysis and characterization of gunshot residues from Brazilian lead-free ammunition. Forensic Sci Int 177(1). https://doi.org/10.1016/j.forsciint.2007.07.005

Mou Y, Lakadwar J, Rabalais JW (2008) Evaluation of shooting distance by AFM and FTIR/ATR analysis of GSR. J Forensic Sci 53(6):1381-1386. https://doi.org/ 10.1111/j.1556-4029.2008.00854.x

Muller D, Levy A, Vinokurov A, Ravreby M, Shelef R, Wolf E et al (2007) A novel method for the analysis of discharged smokeless powder residues. J Forensic Sci 52(1):75-78. https://doi.org/10.1111/j.1556-4029.2006.00309.x

Niewoehner, L. H. (2015). Improved methods for the collection of gunshot residues (GSR) and for chemographic testing of lead-free Sintox ${ }^{\mathrm{TM}}$ ammunition improved methods for the collection of gunshot residues (GSR) and for chemographic testing of lead-free Sintox ${ }^{\text {TM }}$ Ammunition. (April 2003).

Pyl CV, Ovide O, Ho M, Yuksel B, Trejos T (2019) Spectrochimica Acta Part B Spectrochemical mapping using laser induced breakdown spectroscopy as a more objective approach to shooting distance determination. Spectrochimica Acta Part B 152(November 2018):93-101. https://doi.org/10.1016/j. sab.2018.12.010

Santos A, Magalhães T, Vieira DN, Almeida AA, Sousa AV (2007) Firing distance estimation through the analysis of the gunshot residue deposit pattern around the bullet entrance hole by inductively coupled plasma-mass spectrometry: an experimental study. Am J Forensic Med Pathol 28(1):24-30. https://doi.org/10.1097/01.paf.0000233631.40170.d4

Saverio Romolo F, Margot P (2001) Identification of gunshot residue: a critical review. Forensic Sci Int 119(2):195-211. https://doi.org/10.1016/S03790738(00)00428-X

Schwoeble A, Exline DL (2000) Current methods in gunshot residue analysis. CRC Press. https://doi.org/10.1017/CBO9781107415324.004

Tugcu H, Yorulmaz C, Karslioglu Y, Uner HB, Koc S, Ozdemir C et al (2006) Image analysis as an adjunct to sodium rhodizonate test in the evaluation of gunshot residues: an experimental study. Am J Forensic Med Pathol 27(4):296299. https://doi.org/10.1097/01.paf.0000248739.79253.25

Turillazzi E, Di Peri GP, Nieddu A, Bello S, Monaci F, Neri M et al (2013) Analytical and quantitative concentration of gunshot residues ( $\mathrm{Pb}, \mathrm{Sb}, \mathrm{Ba}$ ) to estimate entrance hole and shooting-distance using confocal laser microscopy and inductively coupled plasma atomic emission spectrometer analysis: An experimental study. Forensic Sci Int 231(1-3):142-149. https://doi.org/10. 1016/j.forsciint.2013.04.006

Walther G (2015) Printing insecurity? The security implications of 3D-printing of weapons. Sci Eng Ethics 21(6):1435-1445. https://doi.org/10.1007/ s11948-014-9617-x

Yeung V, Miller DD, Rutzke MA (2017) Atomic absorption spectroscopy, atomic emission spectroscopy, and inductively coupled plasma-mass spectrometry:129-150. https://doi.org/10.1007/978-3-319-45776-5 9

Zapata F, López-lópez M, Manuel J, García-ruiz C (2018) Multi-spectral imaging for the estimation of shooting distances. Forensic Sci Int 282:80-85. https://doi. org/10.1016/j.forsciint.2017.11.025

Zeichner A (2003) Recent developments in methods of chemical analysis in investigations of firearm-related events. Analytic Bioanalytic Chem 376(8):1178-1191. https://doi.org/10.1007/s00216-003-1994-y

Zeichner A, Glattstein B (2002) Recent developments in the methods of estimating shooting distance. ScientificWorldJournal 2:573-585. https://doi.org/10. 1100/tsw.2002.140

Zeichner A, Glattstein B (2006) Improved reagents for firing distance determination, pp 37-41. https://doi.org/10.1080/07370658608011341

\section{Publisher's Note}

Springer Nature remains neutral with regard to jurisdictional claims in published maps and institutional affiliations. 